\title{
The commoditization of the publication culture in Spain: a cost- and time- effective model to systematize Communication Sciences
}

\author{
Eduardo-Francisco Rodríguez-Gómez; Manuel Goyanes
}

How to cite this article:

Rodríguez-Gómez, Eduardo-Francisco; Goyanes, Manuel (2020). "The commoditization of the publication culture in Spain: a cost- and time-effective model to systematize Communication Sciences". Profesional de la información, v. 29, n. 4, e290425.

https://doi.org/10.3145/epi.2020.jul.25

Manuscript received on November 26 2019 Accepted on March $26^{\text {th }} 2020$

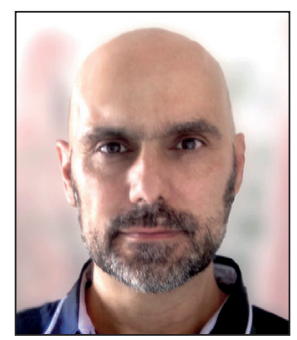

Eduardo-Francisco RodríguezGómez $\square$ https://orcid.org/0000-0002-1788-2412

Universidad Carlos III de Madrid Departamento de Comunicación Madrid, 133

28903 Getafe (Madrid), Spain

edrodrig@hum.uc3m.es

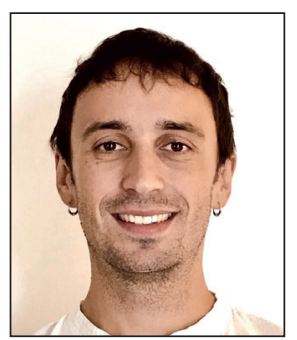

Manuel Goyanes

https://orcid.org/0000-0001-6537-9777

Universidad Carlos III de Madrid

Departamento de Comunicación

Madrid, 133

28903 Getafe (Madrid), Spain

mgoyanes@hum.uc3m.es

\begin{abstract}
This paper explores the current paradigm of the publication culture in Spain, examining the negative and positive forces that shape the dominant dynamics in the production, dissemination and evaluation of scholars' works. Following the intentional sampling of maximum variety, we planned a set of interviews with scholars in the area of communication that represented the heterogeneity of academic ranks, gender, and territories of Spain. The final output consisted of thirty-five semi-structured interviews that took place between May 2018 and May 2019. Scholarship on how researchers and university professors experience publication cultures is abundant, however the national and international studies that address this phenomenon from a holistic approach are practically non-existent. Comprising three actions or systems -production, dissemination and evaluation-, the current publishing culture is depicted as a structure tuned to a set of global-accepted requirements that seem easy to understand and replicate. Under such model, most of the scholars experience discomfort because overproduction is widespread, social transference is rare, and the production and diffusion of scientific works frequently occur at the expense of scholars themselves. The goal seems to be inspired by the cost- and time-effective system of evaluation processes that, despite academics' general opposition, official bodies and university departments have adopted to circumvent the costly task of assessing scientists' outcomes on an individual basis.
\end{abstract}

\section{Keywords}

Publication culture; Communication research; Scientific production; Scientific dissemination; Scholarly communication; Scientific evaluation; Commoditization; Public funding; Academic employment; Scientific transference.

\section{Introduction and literature review}

Scholarship on how researchers and university faculty experience, face and respond to the current publication culture does exist, but it is very limited to certain disciplines of social and natural sciences (Tijdink et al., 2016; Davies; Felappi, 2017). Typically, both the cultural nuances and research practices that shape the publication culture are fractured among the meta-research in communication sciences (Feeley, 2008). This line of inquiry plays a fundamental role in providing statistical insights about a myriad of research indexes that shape the current status of communication scholarship, such as productivity (Griffin et al., 2016), racial inequalities (Chakravartty et al., 2018), and, specially, citation analysis (Levine, 2010). To determine the relevance and theoretical implications of findings, most studies allude to the socio-scientific con-

Acknowledgments

We sincerely thank the experts who participated so generously in this study. 
text in which scholars are immersed and the effects that public administrations and research exercises trigger on productive behavior (Bunz, 2005). However, despite the fact that the publication culture is a structural condition to portray the state of the discipline research output, little research addresses this phenomenon directly.
The establishment of the publish or perish scenario has resulted in researchers being pressured to publish as much as possible in peer-reviewed journals

The exploration of the publication culture is highly related to the growing relevance of the publish or perish imperative and the reproduction of core-periphery dynamics with regard to methodological practice and norms of knowledge dissemination (Gobo, 2011). In contemporary higher education environments, funds and positions are usually awarded through systems that are reliable, objective and efficient (Davis; Felappi, 2017). Scholars and institutions achieve peer recognition by publishing in high reputation journals that are regarded as prestigious (Doyle; Cuthill, 2015) and automated rates are normally used as indicators of individual performance (McGrail; Rickard; Jones, 2006). In this context, research exercises and public funding tend to reward those scholars with the longest CVs and the most publications (Neill, 2008).

However, the establishment of the publish or perish scenario has also resulted in researchers being pressured to publish as much as possible in peer-reviewed journals (Doyle; Cuthill, 2015) in order to get a job, a promotion, or a research grant (Musambira et al., 2012; Adler; Harzing, 2009). More specifically, as Kampourakis (2016, p. 250) observes, it encapsulates a mantra that directly advice scholars on how their career development should be envisioned to be successful, based on: "Either you publish like crazy or you are out of the competition". In this academic environment, research publications have evolved as a kind of "economic currency" (Hilmer; Hilmer, 2009) that determine departmental, individual and institutional rankings (Volkwein; Sweitzer, 2006), but due to the distorting effects that the publish or perish might entail for research output and behavior, this imperative has become a raising subject of criticism and concern among academics (Goyanes; Rodríguez-Gómez, 2018), regardless of geographical location or field of study (Huang; Chang; Chen, 2006; Plümper; Radaelli, 2004). This might include, for instance, the role of scientometrics and indexes in measuring research quality (Bornmann; Haunschild, 2018), the proliferation of articles and publications (Donsbach, 2006), the increasing lack of originality of research contributions (Bauerlein et al., 2010), or the growing isomorphism and standardization of research articles (Alvesson; Gabriel, 2013; Goyanes, 2017). The increasing disequilibrium between requested and available funding also raises concerns about hyper-competitiveness and specialization (Bohm; Peat, 1998), with potential perverting effects on the scientific relevance of publications (Goyanes, 2017) and the growth of questionable research practices (Matthes et al., 2015). The establishment of English as lingua franca for the transmission of scientific knowledge calls also into question the traditional prevalence of regional languages for disseminating research findings, since it usually minimizes the quality of the intellectual contributions (Waisbord; Mellado, 2014; Goyanes, 2017) by omitting an array of cultural contexts, schools and languages (Gunaratne, 2010).

In the context of significant competition for jobs and academic promotion, some argue that the objectification of research evaluations based on quantitative premises have more beneficial than detrimental effects (Thomas, 1996). Others, conversely, argue that scientometrics indicators are a poor substitute for qualitative review and peer assessment (Nightingale; Marshall, 2012) assuming that knowledge dissemination and advancement of science should matter more that indexes or journal impact factors (Lee, 2014). Willmott (2011) referred to this shift as "list fetishism", arguing that the publication outlet (the fetish object), currently assumes an importance greater than the substantive content and contribution of the scholarship. The growing relevance of impact factors and the increasing pressure to publish may be a disincentive to pursue innovative or bold work (De-Rond; Miller, 2005), generating a growing tendency to publish only confirmatory evidence, as

"the system might force scholars to write 'publishable' results at all cost" (Fanelli, 2010, p. 1).

Eventually, the message to aspiring researchers has grown into the publication rule that it no longer matters

"what you write, but only how often, where and with whom you write" (Van-Dalen; Henkens, 2011, p. 2, emphasis of the author).

This imperative has also led to a widespread frustration and dissatisfaction with evaluation systems, as although academics do publish, they may still perish if their publication do not meet the requirements laid down by their universities and public administrations (Lee, 2014).

As a consequence, universities around the world are scrambling for higher international rankings in order to boost their research profiles. Nonetheless, there is academic agreement that the quality of research is decreasing over time, as focusing on quantity means spending less time on each paper (Davies; Felappi, 2017). In a pressure-to-publish context, there seems to exist a massive gap between what most scholars consider to be interesting and what they typically produce and publish (Sword, 2012), and although the official message of journals in publishing is to produce path breaking work and cutting edge research, most articles fail to meet such standards (Cerulo, 2015).

The increasing disequilibrium between requested and available funding raises concerns about hyper-competitiveness and specialization, with potential perverting effects on the scientific relevance of publications 
Studies that explore the publication culture in communication research and social sciences generally address this publish or perish scenario, from both positivist and critical perspectives. While these studies provide insightful knowledge and robust basis for capturing individual perceptions and measuring the prevalence, effects and predictors of this phenomenon, little research has focused on the subtleties of scientists' views and experiences on the publication culture. In this study, we aim to explore and illustrate this subjective perception, addressing the negative and positive forces that shape scholars' academic behavior.

\subsection{The Spanish case}

The Spanish case is relevant for exploring the current publication culture for several reasons. First, it is a paradigmatic case of a Southern-European country adjusting the academic structures and institutions to meet the global demands and mores in research production and evaluation procedures. Communication scholars traditionally tended to focus on critical theory and interpretation, but the transition to empirics reflects the adaptation of the micro or local research standards to the global or macro levels trends and fashions (Goyanes; Rodríguez-Gómez; Rosique-Cedillo, 2018). This phase of consolidation and definition is driven by consecutive reforms in the evaluation systems, a more empirical, positivist and functionalist orthodoxy (Martínez-Nicolás; Saperas-Lapiedra, 2016), and a growing openness to global research practices (Fernández-Quijada; Masip, 2013). As a result, Spain has become an illustrative example of a research culture in transition, reinforcing its impact and diversity in the Ibero-American community and, more discreetly, in the rest of the world (Escribà; Cortiñas, 2013).

Secondly, the Spanish academia is also changing towards a reduced public funding situation, where temporary employment is becoming an extensive standard. In the last decade, governments' expenditure on teaching staff has nearly remained intact despite the fact that professors have almost doubled (Ministerio de Cultura y Deporte, 2018). Tenured personnel have decreased by $18 \%$ while non-tenured have increased by $48 \%$ (Rodríguez-Gómez; Goyanes; Rosique-Cedillo, 2018), and, in addition to an increasing sense of instability, unemployment rate among PhDs has been multiplied by three (INE, 2019). This challenging scenario has triggered systemic dysfunctions that affect researchers in similar terms to what has been observed in other countries, such as pressure and stress to publish (Goyanes; Rodríguez-Gómez, 2018), job frustration (Rodríguez-Martínez, 2014) and underestimation of theoretical works (Perceval; Fornieles-Alcaraz, 2008). Questionable research practices have also prospered, inciting high rates of self-quoting (Fernández-Quijada; Masip; Bergillos, 2013), false authorships (Saperas-Lapiedra; Carrasco-Campos, 2017), or poor methodological transparency (Martínez-Nicolás; Saperas-Lapiedra, 2011).

Lastly, at an initial phase, production, dissemination and evaluation processes in Spain are supervised by Aneca, the National Agency for the Evaluation of Quality and Accreditation. This public institution accounts for the evaluation of university education and the accreditation for civil and non-civil servant bodies. In line with international trends, Aneca's programs have progressively evolved towards an evaluation system based on top-ranked journals and indexes (Aneca, 2017). But if $A$ neca's legal framework is compulsory for all official teaching positions, once scholars pass its assessment, public and private universities enjoy a considerable range of freedom to set recruitment conditions. This system resembles the production and publishing schemes found in other European countries and, for these reasons, we understand that the experiences and perceptions derived from Spanish processes might serve as an illustrative example to other research cultures that are experiencing similar transformations.

\section{Method}

We conducted in-depth semi-structured interviews with 35 Spanish communication scholars between May 2018 and May 2019. The purpose was to find patterns from the "thick descriptions" offered by participants (Hesse-Biber; Leavy, 2006, p. 119), reaching a deep knowledge from a person's "lived experience" and "perspective" (Johnson; Rowlands, 2012, p. 100). To achieve this, we used purposive maximum variety sampling (Patton, 2002), selecting participants with different academic ranks (tenured and non-tenured positions), diverse geographical levels (scholars from eleven Spanish universities), and significant demographics (men and women of different ages and experiences). The final sample represented a full spectrum of work profiles. Among tenured positions, there were 4 senior lecturers, 4 lecturers and 8 associate professors. Among non-tenured positions, there were 9 visiting lecturers, 8 assistant lecturers and 2 PhD holders. Fifty-five percent were men, while forty-five percent were women, and the age of participants ranged from 24 to 64 , although the majority was between 40 and 50 years old. All interviewees demanded confidentiality, so specific affiliations and years of experience were not included and scholar's identification in the text abided by the following code: Tenure (T) or Non-tenure (NT); Male (M) or Female (F); and years of experience $(+10 ;+20 ;+30$, etc.).

\subsection{Interview coding and analysis}

Previous to the official interviews, we conducted two focus groups (with 6 and 7 scholars) and 10 in-depth interviews in order to establish the main discussion themes. In addition to this procedure, we also draw information from the litera- 
ture review. The official interview lasted approximately between 1.5-2 hours until the point when no new or relevant evidence emerged (saturation). At the beginning of the interview, a semi-structured protocol was used to include information about the personal situation of interviewees, an introduction to the subject, and an initial exploration of the reasons why participants are involved in the publication culture.
Scholars describe the production system as a quantitative-driven mechanism where the simplification of science and the absence of social transference result in outcomes of questionable rigor and impact

After this, a more structured interviewed was implemented, prioritizing three basic topics that eventually lead to many interrelated ones: their perception about current research productions, their opinions about the relevance of rankings and journals in career development, and their experiences about the current evaluation system. Although the general agreement and common perspectives arose clearly at an early stage of the interviewing process, we decided to conduct a larger number of interviews to ensure that we had achieved saturation of ideas.

All interviews were recorded and transcribed verbatim following transcription rules proposed by Dresing and Schmieder (2015). In addition, the authors took notes during the sessions to conduct a thematic analysis, following the six-phase analytic procedure of Braun and Clarke (2006) to identify, analyze and report patterns (themes) within data. Codes and thematic maps were discussed with two independent researchers, which then informed the refinement of themes, their definition and naming.

\section{Results}

\subsection{The production system}

Without overextending the abundant literature on the subject, scholars describe the production system as a quantitative-driven mechanism where the simplification of science and the absence of social transference result in outcomes of questionable rigor and impact: "I have evaluated sixteen papers this year but I barely remember one" $(T, M,+20)$. Academics agree that daily research tasks are conformed by a dominant set of prerequisites that seem inevitable if professional goals are to be achieved -IMRaD structure, quantitative methods, empirical evidences-, and most feel forced under this imposed scheme to carry out pre-planned curricular practices, like "studying journals' impact factor" (NT, F, $+5)$, "writing articles using a manual" (NT, M, +10), or "devising strategies to get published" (NT, F, +20). Some of these practices may be considered as questionable research practices, as shown in Table 1.

Table 1. The production system: a serialized model

\begin{tabular}{|l|}
\hline "What do I need? Two papers? Three conferences? An international stay? Ok!" $(N T, M,+10)$. \\
\hline "I must publish twelve JCR for my R\&D project" $(T, M,+20)$. \\
\hline "If I don't have a hypothesis, I make it up" (NT, F, +5). \\
\hline "CVs show off top-ranked indexes, but quality is completely absent" (T, M, +40). \\
\hline "Academics have become workers of an assembly line. A topic can now be divided into three o four papers" (T, M, +15). \\
\hline
\end{tabular}

A minority of scholars accepts this model and describes it as an effective mechanism: "There are problems in the system, but benchmarks are necessary" $(N T, F,+10)$. However, discomfort is common among interviewees and seems to cause two firm reactions. A few opt to walk away from such production practices, researching at their will and publishing in "small publications" (NT, M, +10) that allow "more creative and critical approaches" (NT, M, +5). Aside from this group, the majority recognizes their dependence on the system and accepts it with different levels of conformity, partially compensated by the attainment of merits or additional economic rewards: "I must keep the pace in this tireless hunt for merits, otherwise I'll fall behind" (NT, M, +10); and "If you don't publish in renowned journals, you are nothing. Besides, you always have in mind economic allowances" (NT, F, +5).

\subsection{The dissemination system}

Although described in similar terms to the production system, the dissemination system seems more clearly based on a cost- and time-effective model. Often explained in a tense mood, the most manifested claim concerns academics' inescapable requirement to pay for valid dissemination channels: "We pay for conferences, for memberships, for publishing... We pay to work!" (NT, F, +15$)$. Official standards require scholars to compete in national and international circuits -ideally Anglo-Saxon ones-, but this obligation adds personal extra expenses to the regular ones, such as travel expenses, international stays, and, in the case of non-English speakers, workshops and text translations. The fee that scholars must pay to publish in scientific journals or to get access to scientific contents is also a manifested claim. Three see it as the normal course of action "for publications that seek financial viability" (NT, F, +10), others describe it as a part of a "lucrative businesses" (NT, $M,+10)$ where unpaid tasks are essential for their sustainability: "There are a remarkable number of researchers editing in journals for free" (NT, M, +15). Table 2 shows some of the statements regarding the expensive network of channels that scholars must use to divulge science. 
Table 2. The dissemination system: a cost- and time-effective model

\begin{tabular}{|l|}
\hline "It's a costly system; we pay too much to be published" (NT, F, +10). \\
\hline "These macro-conferences cost a fortune. Plus accommodation, travel expenses, etc." (NT, F, +15). \\
\hline "You have to pay if you want to form part of the dominant system: the Anglo-Saxon one" (NT, M, +5). \\
\hline "Journals' business contradicts the free dissemination of knowledge" (T, M, +20). \\
\hline "There exists a perverse asymmetry between what scholars are required to do and the salaries they earn" (T, F, +35). \\
\hline
\end{tabular}

Regarding top-ranked journals, a few interviewees value them as efficient instruments to detect and enhance science's quality because, "in their own terms" $(N T, F,+10)$, they are "agile and viable means to assess science results" (NT, F, +15$)$. However, the majority seem frustrated at scientific journals for two reasons. First, because they tend "to overestimate quantitative methods and exclude hermeneutic studies" (NT, F, +25), stimulating "an evaluation system based on automated algorithms" ( $T, M,+25)$. And secondly, because the compulsive overproduction of papers, "that nobody minds unless useful for personal deeds" $(F, T,+20)$, is inadequate to transfer Humanities' knowledge into society: "Indices $h$ make you happy, but readers don't really exist" (NT, F, +5$)$.

\subsection{The evaluation system}

The production and the dissemination of science are induced by the evaluation system and its dominant element, the journal impact factor. Most scholars consider applying objective standards as essential for the correct functioning of evaluation processes, since they "optimize peer reviews" (NT, F, +15); "improve methodological practices" $(T, F,+30)$; and "reduce researchers' idleness and favoritism" $(T, M,+15)$. Generally speaking, it is accepted that by adopting impartial evaluation standards, competitiveness increases and science quality improves.

Nonetheless, there appears to be a rejection of this model by most scholars too, since "impact factors don't evaluate the quality of our work, but that of the journals" $(T, M,+25)$ and "local social transference isn't usually considered" (NT, $F,+15)$. Many scientists find it difficult to explain how evaluation criteria work, and define them as "obscure" $(N T, M,+5)$ or "incongruent" (NT, F, +15$)$ or "rigged" $(N T, F,+10)$, so understanding "how evaluators can assess science in these terms" $(T, F,+25)$ seems an unanswered question for many. Being the most significant element of the publication culture, it is notable that none of the scholars is able to explain the manners in which indices are actually fabricated. It is a vague topic where nobody delves. However, despite the fact that scholars tend to explain the system only through its consequences -overproduction (the action of producing too many scientific outcomes encouraged by current evaluation standards), standardization (the process of producing scientific outcomes of the same type with the same basic features), or competitiveness-, many understand the logics of its structure in similar terms to the practices and goals found in market-driven systems (Table 3 ).

Table 3. The commoditization of the evaluation system

\begin{tabular}{l}
\hline "Impact factors work like the Dow Jones of science, an instrument that monetizes scientific value" (T, M, +20$).$ \\
"The corporations that calculate them are private equity firms. Who is really behind science, the academy or the market?" (NT, F, +20$)$. \\
\hline "We are not aware that the submission to the JCR criteria, which are part of an extraordinary business, is leading us to the colonization of scien- \\
tific research by neoliberal thinking" $(\mathrm{T}, \mathrm{M},+30)$. \\
\hline "Impact factors are calculated by private companies that are not accountable to citizens or the scientific community" (NT, M, +10). \\
\hline "Funding programs changed when the government institutionalized the commercialization of the education and scientific systems" (T, M, +25). \\
"As a national and international evaluator, I stopped believing in the transparency of many journals and I am concerned about the commercial \\
drift of others" $(\mathrm{T}, \mathrm{M},+40)$.
\end{tabular}

Along with frustration caused by scientific overproduction and a general disengagement of communication sciences from society, we also observe scholars' disappointment at the hardening of the evaluation criteria that shape current job conditions. Non-tenured scholars stress the negative effects of a constant sense of uncertainty and the rise of temporary employment in a highly competitive scenario: "I don't know of any other work environment that is so demanding, with such a long-term career, and so many obstacles to overcome" (NT, F, +20). As shown in Table 4, many believe that this model prioritizes cost efficiency over academics' employment situation.

Table 4. Job progression and cost efficiency

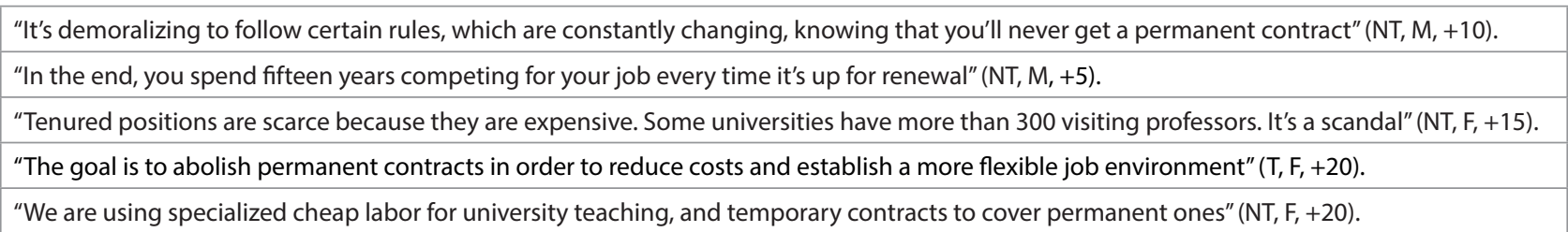

The lack of economic resources for a more stable work environment and the extra expenses that scholars must disburse to produce and disseminate science seem to be the main two reasons as to why all interviewees except three think that public funding in communication sciences is insufficient. Some acknowledge the situation but ignore who may be responsible for it or prefer not 
to discuss it. Others consider it to be "the most important element" $(T, M,+35)$ and put the blame on the government because "having overcome the [last financial] crisis, scientific funding has not arrived" (NT, M, +5). Two professors emphasize the exact amount of public funding that has not reached its beneficiaries in the last R\&D's public solicitation, "up to $70 \%$ " $(\mathrm{T}, \mathrm{M},+30)$, and one of them believes that "the problem is not funding shortage, but terrible management" (NT, $\mathrm{F},+15)$. Overall, funding seems to be a fundamental element within this cost- and time-efficient system.

\section{Discussion}

Interviewees describe the current publishing culture as a structure organized by a set of global-accepted requirements that are easy to recognize and, to some extent, replicate. Most scholars experience discomfort under such structure because it responds to a cost- and time-effective model that seems inadequate to assess communication sciences' production and transference. As effective as logarithmic quantification can be to measure rigor and relevance in Exact Sciences, the model seems inadequate when applied to Social Sciences (Alberts, 2013; Nightingale; Marshall, 2012).

The phenomenon is generally depicted as a mechanism concerning a highly competitive contest. Some, following the quasi-markets theorized by Willmott (1995), describe it in similar terms to the dynamics found in stock markets, where scholars, emulating stockbrokers, follow rivalry patterns to obtain the highest number of shares -published papers- in the most valued corporations -top ranked journals- in order to accumulate wealth -curricular merits- in the shortest period of time and regardless if its beneficial impact on society exists or not. This is what we understand as the commoditization of the publication culture.

In this economy efficiency-driven model, the majority of scholars find it exceptionally difficult to produce and divulge high quality work in national and, especially, international circuits. Besides the colonization of American methods (Chakravartty et al., 2018), the main reasons for this situation are poor funding and deficient management policies (Bolkan et al., 2012). Funding cuts in science have provoked an incremental rise in temporary labor (Rodríguez-Gómez; Goyanes; Rosique-Cedillo, 2018), and an increase in the economic contribution that academics must make to preserve official channels of dissemination, such as journals' fees, conferences' expenses, associations' memberships, international stays, unpaid editing work or review processes, and, in the case of non-English speakers, workshops and texts translations too.

This does not mean that academics do not appreciate an objective model to assess and promote quality in communication sciences. They all welcome impartial evaluation premises and emphasize the advances achieved. However, most disagree with the manners in which such requirements are being applied, because they promote individualistic and aggressive competitiveness (Anderson et al., 2007), cause widespread pressure to publish (Miller; Taylor; Bedeian, 2011), and, although they reduced nepotism and increased scientific quality in their own terms, they have been unable to eradicate impact factor bias (Levine, 2010), eliminate preferential treatment (Ferlazzo; Sdoia, 2012), and establish rigor and social transference as a common standard (Butler; Delaney; Spoelstra, 2017).

When these effects are explained from a personal point of view, scholars feel frustrated because of the imposition of official or unwritten rules against personal motivations. Pressure to publish and job-related stress (De-Rond; Miller, 2005) are fashioned within a system that is mainly disapproved of even at a global scale (Van-Dalen; Henkens, 2012)-, but that scholars sense they must accept. For most of them, extra merits and rewarding measures compensate, only partially, such conformity.

Among these observations, scholars also seem to forget about the importance of their role in the production system (Alvesson, 2012). When asked about the causes for scientific overproduction and questionable research practices, most interviewees seem to perceive questionable research practices (QRP) as the result of an extraneous set of rules that forces them to constant publishing. Nonetheless, other studies have evidenced the fact that scholars are significant elements for the correct functioning of the publication culture (Alvesson; Gabriel; Paulsen, 2017; Fanelli, 2010), thus a more in-depth self-assessment may be one of the key procedures to moderate current overproduction rates, verified by this and earlier research (Donsbach, 2006; Gad-el-Hak, 2004).

In sum, interviewees portray a scenario that requires urgent reform. First, because a system that is based on a costand time-effective model is incompatible with the meticulous and thorough evaluation required by rigorous scientific outputs: as any other system that encourages over-production, it will generate "mediocre, forgettable arguments and findings" (Bauerlein et al., 2010, p. 80). Secondly, because a dissemination system that is unable to sustain itself and relies on academics' payments is highly inefficient to detect actual or potential excellence. A non-self-sufficient system leads to widespread frustration, causing academics to abandon it for personal reasons or to adopt questionable research practices to avoid being left out. Besides, it lacks the necessary resources to avoid hackable gates that may encourage the overproduction of useless scientific findings. And finally, an evaluation system that promotes individualistic competition regardless of its social transference becomes mostly ineffective for all types of agents -citizens, enterprises, or 
administrations- and turns into an expensive mechanism to produce high-quality results. That is, an advanced and costly publishing culture model has been accepted, but scholars continue to perceive and adopt extended QRP (Matthes et al., 2015; Vermeulen; Hartmann, 2015).
A more in-depth self-assessment may be one of the key procedures to moderate current overproduction rates, verified by this and earlier research

\subsection{Proposals and future lines of research}

The general response of official bodies and university departments to this situation has being to harden evaluation criteria (Aneca, 2017), which seems in line with the cost- and time-effective model above described. Sophisticated evaluation procedures are necessary, but a real solution should run through a better-funded evaluation system where specialized channels, under correct supervision, could be established to safeguard science quality according to the times required for its evaluation. This is not about thematic specialization, but about a purpose-driven program that would funnel scientific outcomes into the right dissemination channels, expectantly within an improved funding program that would not only be built upon commercial sources. This being said, for any measure to be successful, those governing must admit that the problem of over-publication is also an institutional one (Davies; Felappi, 2017), and that teaching is half of scholars' inevitable responsibilities and must be coupled with the productive planning of researchers (De-Rond; Miller, 2005).

Concerning overproduction practices, a more comprehensive and focused model could limit the number of papers to the best three-five that a job or promotion candidate can submit (Bauerlein et al., 2010). Regarding unbalanced research-teaching ratios in evaluation processes, a percentage scale could be designed by which scholars could select how to define themselves in respect to academic duties: as researchers, as lecturers, or at managerial positions. Evaluation criteria in recruitment processes could be then applied to specific profiles and in relation to the institution's needs, so academics would conduct a higher number of specific tasks in convenience with their most productive skills. A national survey among academics would determine if this option is economically viable and if it is effective for reorganizing scientific production, reducing the perish-or-publish phenomenon, and raising the quality of research and teaching.

\section{References}

Adler, Nancy J.; Harzing, Anne-Wil (2009). "When knowledge wins: Transcending the sense and nonsense of academic rankings". Academy of management learning and education, v. 8, n. 1, pp. 72-95.

https://journals.aom.org/doi/10.5465/amle.2009.37012181

Alberts, Bruce (2013). "Impact factor distortions". Science, v. 340, n. 6134, p. 787. https://doi.org/10.1126/science.1240319

Alvesson, Mats (2012). "Do we have something to say? From re-search to roi-search and back again". Organization, v. 20, n. 1, pp. 79-90.

https://journals.sagepub.com/doi/10.1177/1350508412460996

Alvesson, Mats; Gabriel, Yiannis (2013). "Beyond formulaic research: In praise of greater diversity in organizational research and publications". Academy of management learning and education, v. 12, n. 2, pp. 245-263. https://journals.aom.org/doi/10.5465/amle.2012.0327

Alvesson, Mats; Gabriel, Yiannis; Paulsen, Roland (2017). Return to meaning: A social science with something to say. London: Oxford University Press. ISBN: 9780198787099

Aneca (2017). Publicación de los criterios de evaluación del programa Academia. https://bit.ly/2K7sViz

Anderson, Melissa S.; Ronning, Emily A.; De-Vries, Raymond; Martinson, Brian C. (2007). "The perverse effects of competition on scientists' work and relationships". Science and engineering ethics, n. 13, pp. 437-461.

https://doi.org/10.1007/s11948-007-9042-5

Bauerlein, Mark; Gad-el-Hak, Mohamed; Grody, Wayne; McKelvey, Bill; Trimble, Stanley W. (2010). "We must stop the avalanche of low-quality research". The chronicle of higher education, June 13.

https://bit.ly/2Y6NOnZ

Bohm, David; Peat, David (1998). Ciencia, orden y creatividad. Las raíces creativas de la ciencia y la vida. Barcelona: Kairós. ISBN: 9788472451841

Bolkan, San; Griffin, Darrin-John; Holmgren, Jennifer-Linn; Hickson III, Mark (2012). "Prolific scholarship in communication studies: Five years in review". Communication education, v. 61, n. 4, pp. 380-394.

https://doi.org/10.1080/03634523.2012.699080

Bornmann, Lutz; Haunschild, Robin (2018). "Do altmetrics correlate with the quality of papers? A large-scale empirical study based on F1000Prime data". PloS one, v. 13, n. 5, e0197133.

https://doi.org/10.1371/journal.pone.0197133 
Braun, Virginia; Clarke, Victoria (2006). "Using thematic analysis in psychology". Qualitative research in psychology, v. 3, n. 2, pp. 77-101.

https://psycnet.apa.org/doi/10.1191/1478088706qp063oa

Bunz, Ulla (2005). "Publish or perish: A limited author analysis of ICA and NCA journals". Journal of communication, v. 55 , n. 4, pp. 703-720.

https://doi.org/10.1111/j.1460-2466.2005.tb03018.x

Butler, Nick; Delaney, Helen; Spoelstra, Sverre (2017). “The gray zone: Questionable research practices in the business school". Academy of management learning and education, v. 16, n. 1, pp. 94-109.

https://doi.org/10.5465/amle.2015.0201

Cerulo, Karen A. (2016). "Why do we publish?". The American sociologist, v. 47, n. 2-3, pp. 151-157. https://doi.org/10.1007/s12108-015-9287-4

Chakravartty, Paula; Kuo, Rachel; Grubbs, Victoria; Mcllwain, Charlton (2018). "\#Communication so white". Journal of communication, v. 68, n. 2, pp. 254-266.

https://doi.org/10.1093/joc/jqy003

Davies, Benjamin; Felappi, Giulia (2017). “Publish or perish”. Metaphilosophy, v. 48, n. 5, pp. 745-761. https://doi.org/10.1111/meta.12269

De-Rond, Mark; Miller, Alan N. (2005). "Publish or perish: bane or boon of academic life?". Journal of management inquiry, v. 14, n. 4, pp. 321-329. https://doi.org/10.1177/1056492605276850

Donsbach, Wolfgang (2006). "The identity of communication research". Journal of communication, v. 56, n. 3, pp. 437-448. https://doi.org/10.1111/j.1460-2466.2006.00294.x

Doyle, Joanne; Cuthill, Michael (2015). “Does 'get visible or vanish' herald the end of 'publish or perish'?". Higher education research and development, v. 34, n. 3, pp. 671-674.

https://doi.org/10.1080/07294360.2015.1025467

Dresing, Thorsten; Pehl, Thorsten; Schmieder, Christian (2015). Manual (on) transcription: Transcription conventions, software guides and practical hints for qualitative researchers ( $\left.3^{\text {rd }} \mathrm{ed}.\right)$.

https://bit.ly/1J6c7k5

Escribà, Eudald; Cortiñas, Sergi (2013). "Internationalization and coauthorship in major communication journals in Spain". Comunicar, v. 21, n. 41, pp. 35-44.

https://doi.org/10.3916/C41-2013-03

Fanelli, Danielle (2010). "Do pressures to publish increase scientists' bias? An empirical support from US states data". PloS one, v. 5, n. 4, e10271. https://doi.org/10.1371/journal.pone.0010271

Feeley, Thomas H. (2008). "A bibliometric analysis of communication journals from 2002 to 2005". Human communication research, v. 34, n. 3, pp. 505-520. https://doi.org/10.1111/j.1468-2958.2008.00330.x

Ferlazzo, Fabio; Sdoia, Stefano (2012). "Measuring nepotism through shared last names: Are we really moving from opinions to facts?". PLoS one, v. 7, n. 8, e43574.

https://doi.org/10.1371/journal.pone.0043574

Fernández-Quijada, David; Masip, Pere (2013). "Three decades of Spanish communication research: Towards legal age". Comunicar, v. 21, n. 41, pp. 15-24.

https://doi.org/10.3916/C41-2013-01

Fernández-Quijada, David; Masip, Pere; Bergillos, Ignacio (2013). “El precio de la internacionalidad: la dualidad en los patrones de publicación de los investigadores españoles en comunicación". Revista española de documentación científica, v. 36, n. 2, e10.

https://doi.org/10.3989/redc.2013.2.936

Gad-el-Hak, Mohamed (2004). "Publish or perish - An ailing enterprise?”. Physics today, v. 57, n. 3, pp. 61-64. https://doi.org/10.1063/1.1712503

Gobo, Giampietro (2011). "Glocalizing methodology? The encounter between local methodologies". International journal of social research methodology, v. 14, n. 6, pp. 417-437.

https://doi.org/10.1080/13645579.2011.611379

Goyanes, Manuel (2017). Desafío a la investigación estándar en comunicación: Crítica y alternativas. Barcelona: Editorial UOC. Colección EPI Scholar. ISBN: 9788491166757 
Goyanes, Manuel; Rodríguez-Gómez, Eduardo-Francisco (2018). “¿Por qué publicamos? Prevalencia, motivaciones y consecuencias de publicar o perecer". El profesional de la información, v. 27, n. 3, pp. 548-558.

https://doi.org/10.3145/epi.2018.may.08

Goyanes, Manuel; Rodríguez-Gómez, Eduardo-Francisco; Rosique-Cedillo, Gloria (2018). "Investigación en comunicación en revistas científicas en España (2005-2015): de disquisiciones teóricas a investigación basada en evidencias". El profesional de la información, v. 27, n. 6, pp. 1281-1291.

https://doi.org/10.3145/epi.2018.nov.11

Griffin, Darrin J.; Bolkan, San; Holmgren, Jennifer L.; Tutzauer, Frank (2016). “Central journals and authors in communication using a publication network". Scientometrics, v. 106, n. 1, pp. 91-104.

https://doi.org/10.1007/s11192-015-1774-4

Gunaratne, Shelton A. (2010). "De-Westernizing communication/social science research: Opportunities and limitations". Media, culture and society, v. 32, n. 3, pp. 473-500.

https://doi.org/10.1177/0163443709361159

Hesse-Biber, Sharlene; Leavy, Patricia L. (2006). The practice of qualitative research. London: Sage, 403 Seiten.

Hilmer, Michael J.; Hilmer, Christiana E. (2009). "Fishes, ponds, and productivity: student-advisor matching and early career publishing success for economics PhDs". Economic inquiry, v. 47, n. 2, pp. 290-303.

https://doi.org/10.1111/j.1465-7295.2007.00108.x

Huang, Mu-Hsuan; Chang, Han-Wen; Chen, Dar-Zen (2006). "Research evaluation of research-oriented universities in Taiwan from 1993 to 2003". Scientometrics, v. 67, n. 3, pp. 419-435.

https://doi.org/10.1556/Scient.67.2006.3.6

INE (2019). Encuesta población activa: resultados anuales. Instituto Nacional de Estadística.

https://www.ine.es/dyngs/INEbase/es/operacion.htm?c=Estadistica_C\&cid=1254736176918\&menu=resultados\&i$d p=1254735976595$

Johnson, John M.; Rowlands, Timothy (2012). "The interpersonal dynamics of in-depth interviewing”. In: Gubrium, Jaber F.; Holstein, James A.; Marvasti, Amir B.; McKinney, Karyn D. (eds.). The SAGE handbook of interview research: The complexity of the craft, $2^{\text {nd }}$ ed. Thousand Oaks: Sage, pp. 99-113.

https://doi.org/10.4135/9781452218403.n7

Kampourakis, Kostas (2016). “Publish or perish?”. Science and education, v. 25, n. 3-4, pp. 249-250. https://doi.org/10.1007/s11191-016-9828-4

Lee, Icy (2014). "Publish or perish: The myth and reality of academic publishing”. Language teaching, v. 47, n. 2, pp. $250-261$. https://doi.org/10.1017/S0261444811000504

Levine, Timothy R. (2010). "Rankings and trends in citation patterns of communication journals". Communication education, v. 59, n. 1, pp. 41-51.

https://doi.org/10.1080/03634520903296825

Martínez-Nicolás, Manuel; Saperas-Lapiedra, Enric (2011). “La investigación sobre Comunicación en España (1998-2007). Análisis de los artículos publicados en revistas científicas”. Revista latina de comunicación social, n. 66, pp. 101-129. http://www. revistalatinacs.org/11/art/926 Vicalvaro/05 Nicolas.html

Martínez-Nicolás, Manuel; Saperas-Lapiedra, Enric (2016). “Objetos de estudio y orientación metodológica de la reciente investigación sobre comunicación en España (2008-2014): Análisis de los trabajos publicados en revistas científicas españolas". Revista latina de comunicación social, n. 71, pp. 1365-1384.

http://www.revistalatinacs.org/071/paper/1150/70es.html

Matthes, Jörg; Marquart, Franziska; Naderer, Brigitte; Arendt, Florian; Schmuck, Desirée; Adam, Karoline (2015). "Questionable research practices in experimental communication research: A systematic analysis from 1980 to 2013 ". Communication methods and measures, v. 9, n. 4, pp. 193-207.

https://doi.org/10.1080/19312458.2015.1096334

Ministerio de Cultura y Deporte (2018). Datos y cifras del Sistema universitario español. https://bit.ly/2DiNsy1

McGrail, Matthew R.; Rickard, Claire M.; Jones, Rebecca (2006). "Publish or perish: A systematic review of interventions to increase academic publication rates". Higher education research and development, v. 25, n. 1, pp. 19-35. https://doi.org/10.1080/07294360500453053

Miller, Allan N.; Taylor, Shannon G.; Bedeian, Arthur G. (2011). "Publish or perish: academic life as management faculty live it". Career development international, v. 16, n. 5, pp. 422-445.

https://doi.org/10.1108/13620431111167751 
Musambira, George; Collins, Steven; Brown, Tim; Voss, Kimberly (2012). "From publish or perish to grant or perish: Examining grantsmanship in communication and the pressures on communication faculty to procure external funding for research". Journalism \& mass communication educator, v. 67, n. 3, pp. 234-251.

https://doi.org/10.1177/1077695812454109

Neill, Ushma S. (2008). "Publish or perish, but at what cost?". The journal of clinical investigation, v. 118, n. 7, pp. 2368. https://doi.org/10.1172/JCl36371

Nightingale, Julie M.; Marshall, Gill (2012). "Citation analysis as a measure of article quality, journal influence and individual researcher performance". Radiography, v. 18, n. 2, pp. 60-67.

https://doi.org/10.1016/j.radi.2011.10.044

Patton, Michael-Quinn (2002). Qualitative research and evaluation methods. London: Sage publications. ISBN: 9780 761919711

Perceval, José-María; Fornieles-Alcaraz, Javier (2008). “Confucio contra Sócrates: la perversa relación entre la investigación y la acreditación". Anàlisi, n. 36, pp. 213-224.

https://www.raco.cat/index.php/Analisi/article/view/94533

Plümper Thomas; Radaelli, Claudio (2004). "Publish or perish? Publications and citations of Italian political scientists in international political science journals, 1990-2002". Journal of European public policy, v. 11, n. 6, pp. 1112-1127.

https://doi.org/10.1080/1350176042000298138

Rodríguez-Gómez, Eduardo-Francisco; Goyanes, Manuel; Rosique-Cedillo, Gloria (2018). “Communication research in Spain: labor temporality, intensive production and competitiveness". Communication \& society, v. 31, n. 4, pp. $229-242$. http://dadun.unav.edu/handle/10171/55751

Rodríguez-Martínez, Carmen (2014). "La proletarización del profesorado en la Lomce y en las nuevas políticas educativas: de actores a culpables". Revista interuniversitaria de formación del profesorado, n. 81, pp. 73-87.

https://dialnet.unirioja.es/servlet/articulo?codigo $=5009072$

Saperas-Lapiedra, Enric; Carrasco-Campos, Ángel (2017) “¿Cómo investigamos la comunicación en España? La producción científica en revistas especializadas (1990-2014). Métodos y técnicas de investigación”. In: IV Congreso Nacional de Metodología de la Investigación en Comunicación, Universitat Jaume I, Castellón, Spain.

Sword, Hellen (2012). Stylish academic writing. Harvard, MA: Harvard University Press. ISBN: 9780674064485

Thomas, Leon G. (1996). "The two faces of competition: Dynamic resourcefulness and the hypercompetitive shift". Organization science, v. 7, n. 3, pp. 221-242.

https://doi.org/10.1287/orsc.7.3.221

Tijdink, Joeri K.; Schipper, Katherine; Bouter, Lex M.; Pont, P. Maclaine; De-Jonge, Jos; Smulders, Yvo M. (2016). “How do scientists perceive the current publication culture? A qualitative focus group interview study among Dutch biomedical researchers". BMJ open, v. 6, n. 2.

https://doi.org/10.1136/bmjopen-2015-008681

Van-Dalen, Hendrik P.; Henkens, Kène (2012). "Intended and unintended consequences of a publish-or-perish culture: A worldwide survey". Journal of the American Society for Information Science and Technology, v. 63, n. 7, pp. $1282-1293$. https://doi.org/10.1002/asi.22636

Vermeulen, Ivar; Hartmann, Tilo (2015). "Questionable research and publication practices in communication science". Communication methods and measures, v. 9, n. 4, pp. 189-192.

https://doi.org/10.1080/19312458.2015.1096331

Volkwein, J. Fredericks; Sweitzer, Kyle V. (2006). “Institutional prestige and reputation among research universities and liberal arts colleges". Research in higher education, v. 47, n. 2, pp. 129-148.

https://doi.org/10.1007/s11162-005-8883-5

Waisbord, Silvio; Mellado, Claudia (2014). "De-Westernizing communication studies: A reassessment". Communication theory, v. 24, n. 4, pp. 361-372.

https://doi.org/10.1111/comt.12044

Willmott, Hugh (1995). "Managing the academics: Commoditization and control in the development of university education in the U.K.". Human relations, v. 48, n. 9, pp. 993-1021.

https://doi.org/10.1177/001872679504800902

Willmott, Hugh (2011). "Journal list fetishism and the perversion of scholarship: reactivity and the ABS list". Organization, v. 18, n. 4, pp. 429-442.

https://doi.org/10.1177/1350508411403532 